\title{
Fault Parameters and Tsunami Excitation of the May 13, 1993, Shumagin Islands Earthquake
}

\author{
Yuichiro Tanioka, Kenji Satake, Larry Ruff \\ Department of Geological Sciences, University of Michigan \\ Frank González \\ Pacific Marine Environmental Laboratory, National Oceanic and Atmospheric Administration
}

\begin{abstract}
The Shumagin Islands earthquake of May 13, 1993, occurred in a previously identified seismic gap where a large subduction earthquake is expected. We analyzed long-period surface waves and $P$ waves recorded on the IRIS stations to estimate the fault parameters. The Centroid Moment Tensor solution shows that the focal mechanism is a thrust type with the strike parallel to the Aleutian trench. The seismic moment is $\mathbf{2 . 0}$ $\times 10^{19} \mathrm{Nm}$ and the corresponding moment magnitude is 6.8 . The Moment Tensor Rate Function inversion from $P$ waves also yields a similar focal mechanism and seismic moment. In addition, this computation provides estimates of $10 \mathrm{~s}$ for the duration of the source time function and $35 \mathrm{~km}$ for the best point source depth. These seismological analyses indicate that the fault mechanism of the 1993 earthquake was as expected, but that the magnitude was too small to fill the gap. This earthquake did not generate a tsunami large enough to be observed at the Sand Point, Alaska tide gauge or at an ocean bottom pressure gauge, at distances of 100 and $300 \mathrm{~km}$, respectively. Numerical tsunami simulations result in amplitudes at both stations that are within the background noise level. Additional numerical experiments also suggest that the small tsunami amplitudes are due to the location of the source area in the shallow shelf region.
\end{abstract}

\section{Introduction}

The Shumagin seismic gap has been identified for some time as a region between the rupture areas of the 1938 Alaskan and 1946 Aleutian earthquake (Figure 1, inset). Davies et al. [1981] suggested that the gap could be broken by a series of large earthquakes with $M_{w}$ of 7.2 to 7.8 , or in a single great event of $M_{W}$ 8.4. In more recent analyses, Nishenko and Jacob [1990] and Nishenko [1991] suggest that a gap-filling event will have an expected magnitude of 7.4, with conditional probabilities of $27 \%$, $48 \%$, and $75 \%$ of occurring during the 5-, 10-, and 20 -year periods that end in 1994, 1999, and 2009, respectively. Both the $1938\left(M_{W}\right.$ 8.2) and $1946\left(M_{s} 7.4\right)$ earthquakes generated Pacificwide tsunamis and the expected earthquake in the Shumagin gap would almost certainly generate a large tsunami.

Recently, on 13 May 1993, a large earthquake did occur near the Shumagin Islands, Alaska. The NEIS Preliminary Determination of Epicenters (PED) provides the following estimates: origin time, 11:59:49.2 GMT; epicenter, $55.177^{\circ} \mathrm{N}$, $150.458^{\circ} \mathrm{W}$; depth, $32 \mathrm{~km}$; magnitude, $M_{s}$ 6.8. The Harvard

Copyright 1994 by the American Geophysical Union.

Paper number 94GL00875

0094-8534/94/94GL-00875\$03.00
Quick CMT (Centroid Moment Tensor) solution also provides the following estimates: origin time, 11:59:57.3 GMT; epicenter, $54.62^{\circ} \mathrm{N}, 159.83^{\circ} \mathrm{W}$; depth, $38.5 \mathrm{~km}$; seismic moment, $2.5 \times$ $10^{19} \mathrm{Nm}$. This earthquake did not generate an observable tsunami signal on either a tide gauge or a bottom pressure recorder located within 100 and $300 \mathrm{~km}$, respectively, of the epicenter (Figure 1).

In this paper, we use seismic surface waves and body waves to provide additional estimates of fault parameters for this earthquake, and compare our results with the fault mechanism and magnitude that might be expected in the Shumagin Seismic Gap on the basis of regional tectonics and previous analysis by other investigators. We also compute synthetic tsunami to better understand the lack of a detectable tsunami signal at the two nearby sea level stations.

\section{Surface wave analysis}

We performed the CMT inversion [Dziewonski et al., 1981; Fukushima et al., 1989] using long-period surface waveforms recorded at 12 IRIS network stations (ANTO, CHTO, COL, HRV, KIP, MAJO, PAB, PAS, RAR, SNZO, TATO, and TUC). The result of this computation is summarized in Table 1 . The $T$ axis is $-2.1 \times 10^{19} \mathrm{Nm}$ ( plunge $78^{\circ}$, azimuth $333^{\circ}$ ), the $P$-axis is $2.0 \times 10^{19} \mathrm{Nm}$ (plunge $12^{\circ}$, azimuth $161^{\circ}$ ), and the $\mathrm{N}$-axis is 0.1 $\times 10^{19} \mathrm{Nm}$. The deviation from double couple, as indicated by the ratio of the minimum (absolute value) to the maximum eigenvalue, is 0.02 , and the value of the seismic moment is $2.0 \times$ $10^{19} \mathrm{Nm}$. The centroid time shift is $9 \mathrm{~s}$. The focal mechanism is a thrust type, with a shallow dip angle of $33^{\circ}$ and a strike of $253^{\circ}$ (Figure 2a). Hence, the earthquake was a subduction event, with strike parallel to the Aleutian trench, as would be expected to occur in this gap. However, the moment magnitude, $M_{W} 6.8$, is significantly smaller than either the 7.4 expected value of Nishenko [1990] or the $7.2-8.4$ range of values suggested by Davies et al. [1981].

\section{Body wave analysis}

We performed the Moment Tensor Rate Function (MTRF) inversion [Ruff and Tichelaar, 1990] using broadband $P$ waves recorded at 12 stations. We used the first $40 \mathrm{~s}$ of $\mathrm{P}$ wave, filtered with a $2 \mathrm{~s}$ duration triangle. The MTRFs are sampled at $2 \mathrm{~s}$ interval: We first performed the MTRF inversion with a $P$ velocity of $6.7 \mathrm{~km} / \mathrm{s}$ and a density of $2.7 \mathrm{~g} / \mathrm{cm}^{3}$ to find the best depth. Figure 3 shows the correlation coefficient between synthetic and observed seismograms as a function of depth. The best point source depth is $35 \mathrm{~km}$. The best double couple mechanism reduced from the MTRFs for the best depth is shown in Figure $2 \mathrm{~b}$ (strike $57^{\circ}$, dip $71^{\circ}$, rake $86^{\circ}$ ). We determined a 


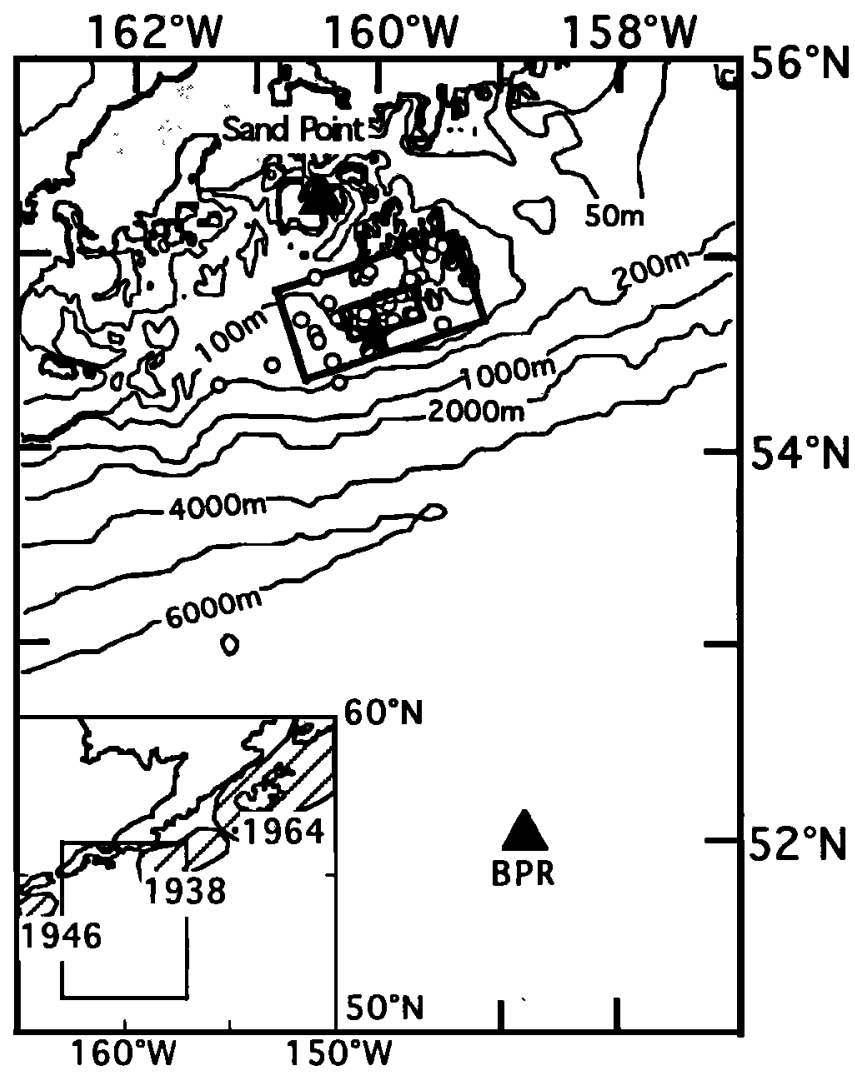

Figure 1. Map of the source region. A star is the epicenter of the main shock and open circles are aftershocks from Lu ct al. [1994]. Two triangles are a tide gauge station at Sand Point and the bottom pressure recorder (BPR). The rectangles are the two faults which are used for the synthetic tsunami computation. Inset map shows the Alaskan peninsula with aftershock areas of the recent large earthquakes.

single source time function from the re-inversion of the seismograms with a fixed double couple mechanism obtained by the MTRF inversion. Figure 4 shows the single source time function which is basically one dominant pulse of $10 \mathrm{~s}$ duration. The seismic moment of the main pulse is $1.4 \times 10^{19} \mathrm{Nm}$ which is slightly smaller than that from surface waves. The moment magnitude $M_{W}$ is 6.7 . It suggests that $70 \%$ of the moment was released in the first ten seconds. If we assume a bilateral rupture with velocity of $3 \mathrm{~km} / \mathrm{s}$, the rupture length in first ten seconds is $60 \mathrm{~km}$. If the rupture is unilateral or the velocity is less than $3 \mathrm{~km} / \mathrm{s}$, the rupture length becomes smaller.

\section{Tidal gauge and bottom pressure record analysis}

There is a tide gauge station at Sand Point, within $100 \mathrm{~km}$ of the epicenter, maintained by NOAA's National Ocean Service (Figure 1). The record is presented in Figure $5 \mathrm{a}$ for a $3.5 \mathrm{~h}$ period beginning $0.5 \mathrm{~h}$ before the main shock. No tsunami signal is evident against the background noise level, which is on the order of a few $\mathrm{cm}$. Figure $5 \mathrm{~b}$ presents bottom pressure recorder (BPR) data acquired by the NOAA/PMEL Tsunami Project [Gonzalez et al., 1987] at a station located $300 \mathrm{~km}$ south of the epicenter at a depth of $4700 \mathrm{~m}$ (Figure 1). The BPR acquires a $15 \mathrm{~s}$ average pressure value every $15 \mathrm{~s}$, with a sensitivity equivalent to less than $1 \mathrm{~mm}$ of water height. We have eliminated the tide from the original record by subjecting it to a highpass filter with a comer period of 1 hour.
Table 1. CMT solution

\begin{tabular}{|c|c|}
\hline Moment tensor elements & $\left(10^{19} \mathrm{Nm}\right)$ \\
\hline $\mathbf{M}_{\mathbf{r}}$ & 1.84 \\
\hline $\mathbf{M}_{\mathbf{6 0}}$ & -1.68 \\
\hline Mu & -1.55 \\
\hline$M_{r \theta}$ & 0.79 \\
\hline $\mathbf{M}_{\mathrm{r}}$ & 0.34 \\
\hline $\mathbf{M}_{0}$ & -0.58 \\
\hline
\end{tabular}

\begin{tabular}{|c|c|}
\hline \multicolumn{2}{|l|}{ Best double couples } \\
\hline $\begin{array}{l}M_{0} \\
\varepsilon\end{array}$ & $\begin{array}{c}2.0 \times 10^{19} \mathrm{Nm} \\
0.02\end{array}$ \\
\hline $\begin{array}{l}\text { strike } \\
\text { dip } \\
\text { slip }\end{array}$ & $\begin{array}{rr}69^{\circ} & 253^{\circ} \\
57^{\circ} & 33^{\circ} \\
88^{\circ} & 93^{\circ}\end{array}$ \\
\hline
\end{tabular}

The largest amplitude wave with an apparent period of about $60 \mathrm{~s}$ (4 samples) is seen to arrive at the BPR station about five minutes after the origin time of the earthquake. Thus, the group velocity of this wave is about $1 \mathrm{~km} / \mathrm{s}$. This is not a tsunami since the average speed of a tsunami is only about $0.2 \mathrm{~km} / \mathrm{s}$ at oceanic depths. Bradner [1962] and Filloux [1982] demonstrated that a bottom pressure gauge can record seismic surface waves. However, a mantle Rayleigh wave of $60 \mathrm{~s}$ period is characterized by a group velocity of about $4 \mathrm{~km} / \mathrm{s}$ [e.g. Dziewonski and Anderson, 1981], much too fast to provide an explanation for this large wave. Since the simple averaging scheme employed by the BPR does not entirely eliminate aliasing, one possible explanation is that this energy is actually due to the aliasing of higher frequency wave energy. Oceanic Rayleigh waves may be the explanation for the observed wave energy. For such a wave, the group velocity can be estimated from a theoretical dispersion curve for a liquid layer over a basaltic ocean [e.g., Ewing et al., 1957]. Assuming a $4000 \mathrm{~m}$ deep ocean, the dispersion curve indicates that the minimum group velocity (Airy phase) is about 1 $\mathrm{km} / \mathrm{s}$ at periods of about 8 to $10 \mathrm{~s}$. Thus, under-sampling of such a wave by the BPR might produce the aliased record as observed. However, given our under-sampled glimpse of these waves, we can not pursue further quantitative study of this observation.

\section{Tsunami computations}

We computed synthetic tsunamis for two fault models: the first with length and width of $100 \mathrm{~km} \times 50 \mathrm{~km}$, the second with dimensions $40 \mathrm{~km} \times 15 \mathrm{~km}$ (see Figure 1). The larger fault plane covers most of the aftershocks located by Lu et al. [1994], while a) CMT inversion

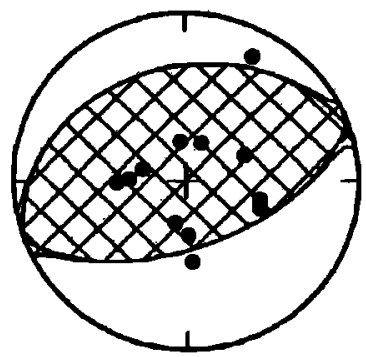

Mo $=2.0 \times 10^{19} \mathrm{Nm}$ b) MTRF inversion

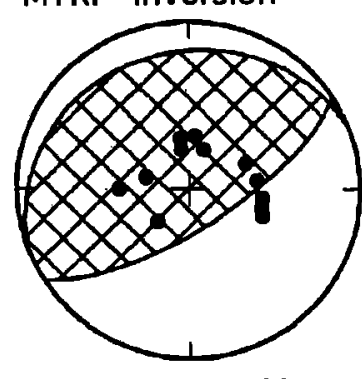

Figure 2. a) The solution of CMT inversion. b) The solution of MTRF inversion. Station distributions are plotted on the focal sphere. 


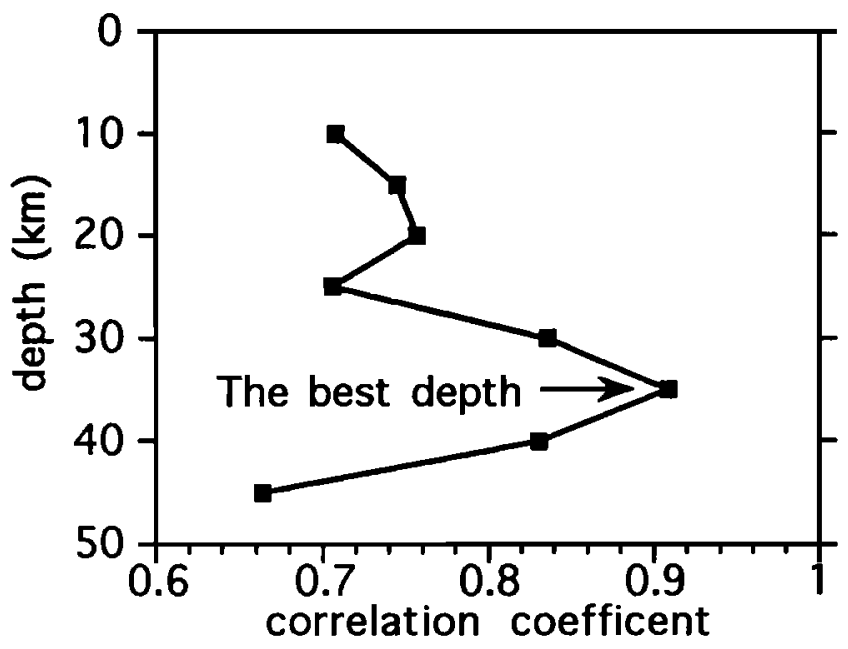

Figure 3. The correlation coefficient between observed and synthetic seismograms are plotted for various point source depths.

the smaller covers a more restricted region in which aftershocks are concentrated. For the seismic moment of $2.0 \times 10^{19} \mathrm{Nm}$ determined from surface wave analysis and a rigidity of $4 \times 10^{10}$ $\mathrm{N} / \mathrm{m}^{2}$, the average slip for the large and small faults are calculated to be $10 \mathrm{~cm}$ and $80 \mathrm{~cm}$, respectively. Stress drop estimates range from 1 to 36 bars for these fault models. Vertical crustal deformation caused by the faulting was computed using the method of Okada [1985], and this pattern was used as the initial condition for our simulation. The synthetic tsunami waveforms were then computed by integrating the nondispersive linear long wave equations over region shown in Figure 1, using

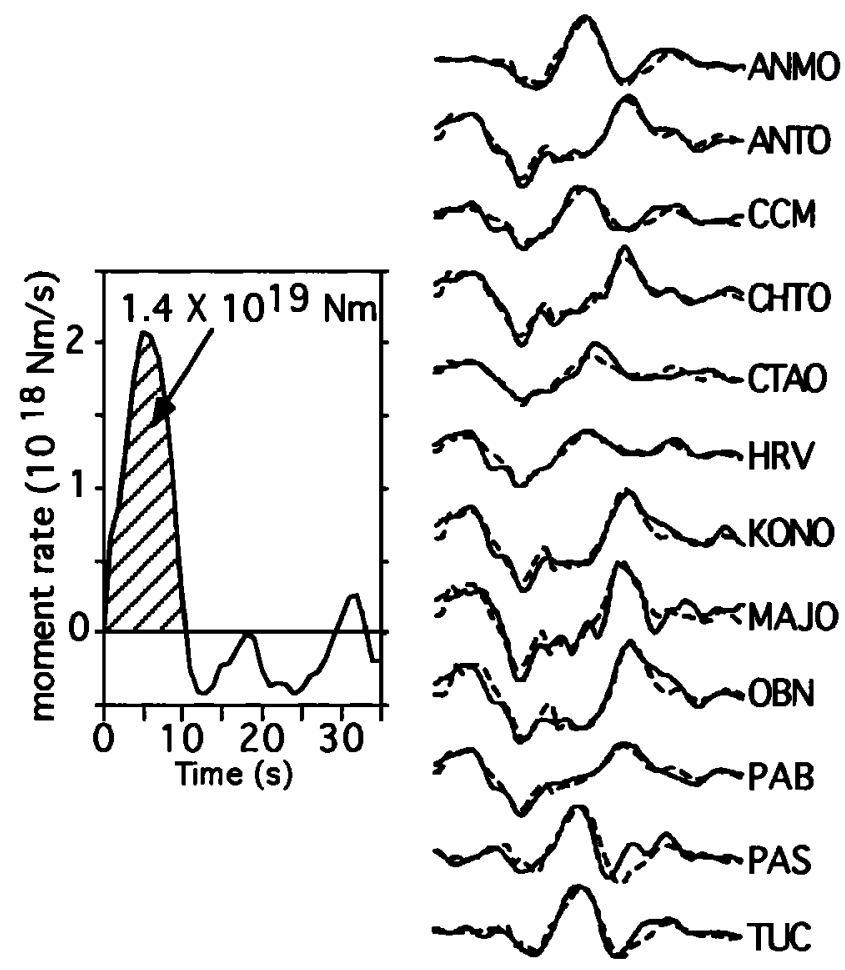

Figure 4. Left part shows the source time function with the seismic moment of the shaded area. Right part shows the observed seismograms (solid line) and synthetic seismograms (dash line) with station names. a) Tide gauge (Sand point) observed synthe tic (small fault)

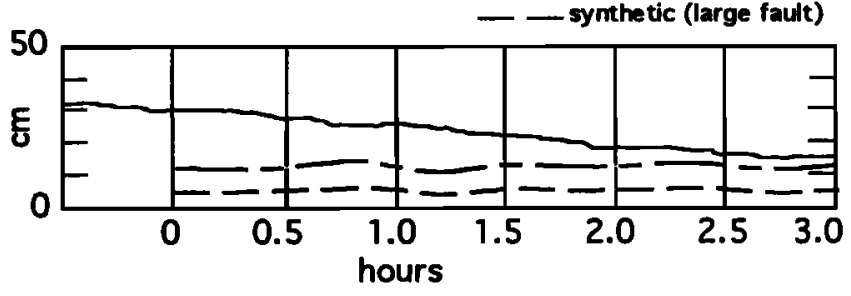

b) Bottom pressure recorder

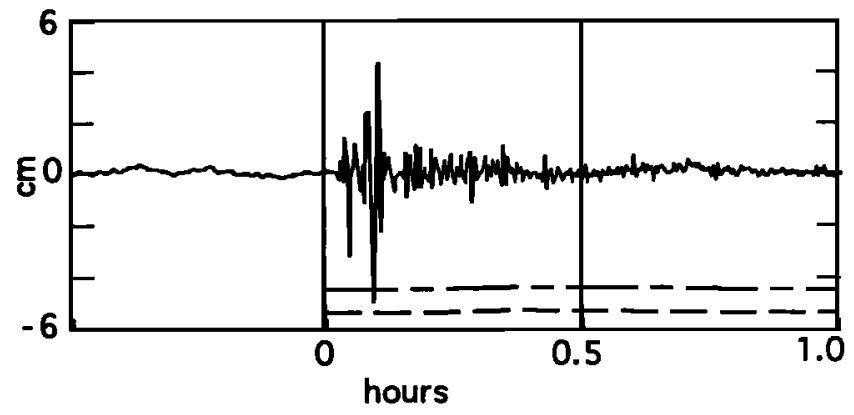

Figure 5. a) Tide gauge record at Sand Point (solid line) and two synthetic tsunamis for large and small fault which are shown in Figure 1. b) Bottom pressure record and two synthetic tsunamis. For clarity, all synthetic tsunami records have been displaced on the vertical axis.

a finite difference scheme [Aida, 1978; Satake, 1985] on a $1 \mathrm{~min}$ $\times 1 \mathrm{~min}$ (about $2 \mathrm{~km} \times 1 \mathrm{~km}$ ) computational grid.

The resulting synthetic tsunami records at Sand Point and the BPR are shown in Figure 5. The maximum tsunami amplitude at Sand Point for the large and small faults are 2.7 and $3.6 \mathrm{~cm}$, respectively, within the background noise level. The maximum amplitude at the BPR location for the large and small faults are 0.09 and $0.07 \mathrm{~cm}$, respectively, which are also within the noise level. From these results, we conclude that the seismic moment and rupture area estimates are consistent with the observed absence of a tsunami signal.

\section{Discussion}

We have seen that the synthetic tsunami wave at the BPR station is more than an order of magnitude smaller than the synthetic wave at the tide gauge station. This is probably due to the shallow water depth, less than $\mathbf{2 0 0} \mathrm{m}$, of the epicentral area (see Figure 1). Most of the tsunami energy could be trapped on the continental shelf, in the form of an edge wave [LeBlond and Mysak, 1978] or ridge wave [Satake et al., 1992]. Hence the BPR did not record a significant tsunami, although it is much more sensitive than the tide gauge. To explore this possibility further, we performed an additional simulation with the smaller fault as the source, but relocated to the trench, about $100 \mathrm{~km}$ south of the estimated epicenter. This simulation produced synthetic tsunami amplitudes of $4.0 \mathrm{~cm}$ at Sand Point and $0.8 \mathrm{~cm}$ at the BPR, with periods and waveforms which are significantly different from the previous simulations. Thus, the deep ocean source produces a larger synthetic tsunami at Sand Point, despite the longer travel distance. But we also see that the synthetic tsunami amplitude at the BPR is an order of magnitude smaller for the continental shelf source compared to the deep ocean source, consistent with the hypothesized trapping of the tsunami energy on the shelf. 
Other earthquakes in this region that were previously studied are: April 6, 1974, February 14, 1983, and October 9, 1985. The depth of the 1974 event is $40 \mathrm{~km}$ [Tichelaar and Ruff, 1993]. The depths of the 1983 and 1985 events are $26 \mathrm{~km}$ [Taber and Beavan, 1986] and $30 \mathrm{~km}$ [Person, 1986], respectively. Our large fault model for the May 13, 1993 earthquake is located trenchward from the epicenter of the 1974 event and just arcward from the 1983 and 1985 events, which were adjacent to each other. Thus, our best depth of $35 \mathrm{~km}$ for the 1993 event is consistent with these previous studies. Lisowski et al. [1988] suggest that the 1983 and 1985 earthquakes may represent partial ruptures at the down-dip edge of the coupled zone. We suggest that the 1993 earthquake also ruptured at the down-dip edge of the coupled zone. Furthermore, the rupture length of the 1993 earthquake is likely to be $40-60 \mathrm{~km}$, much shorter than the Shumagin seismic gap, $280 \mathrm{~km}$. Therefore, this earthquake did not fill the Shumagin gap.

It is also important to understand why the tsunami is so small. We find that in addition to the small moment and large depth, the location of the source beneath the continental shelf is also an important factor in producing a small tsunami. This contrasts with the 1992 Nicaragua earthquake which was characterized by a large slip near the trench and produced large tsunamis [Satake. 1993].

Acknowledgments. We thank J. Johnson for helpful comments. The preliminary CMT solution was provided by G. Ekstrom and M. Salganik of Harvard. The Sand Point tide gauge record was provided by NOAA's Alaska Tsunami Warning Center. Partial support for the PMEL Tsunami Project network of bottom pressure recorders is provided by NOAA's Coastal Ocean Program. Earthquake and tsunami research at the University of Michigan is supported by the National Science Foundation (EAR-9117800, EAR-9019003) and the U.S. Geological Survey (143493-G-2320).

\section{References}

Aida, I., Reliability of a tsunami source model derived from fault parameters, J. Phys. Earth, 26, 57-73, 1978.

Brandner, H., Pressure variations accompanying a plane wave propagated along the ccean bottom, J. Geophys. Res., 67, 3631-3633, 1962.

Davies, J., L. Sykes, L. House, and K. Jacob, Shumagin seismic gap, Alaska peninsula: history of great earthquakes, tectonic setting, and evidence for high seismic potential, J. Geophys. Res., 86, 3821-3855, 1981.

Dziewonski, A.M., and D.L. Anderson, Preliminary reference Earth model., Earth Planet. Inter., 25, 297-356, 1981.

Dziewonski, A.M., T.A. Chou, and J.H. Woodhouse, Determination of earthquake source parameters from waveform data for studies of global and regional seismicity, J. Geophys. Res., 86, 2825-2853, 1981.

Ewing, W.M., W.S. Jardetzky, and F. Press, Elastic wave in layered media, McGraw-Hill book company, 1957.
Filloux, J.H., Tsunami recorded on the open ocean floor, Geophys. Res. Letr., 9, 25-28, 1982.

Fukushima, T., D. Suetsugu, I. Nakanishi, and I. Yamada, Moment tensor inversion for near earthquakes using long-period digital seismographs, J. Phys. Earth, 37, 1-29, 1989.

Gonzalez, F.I., E.N. Bernard, H.B. Milburn, D. Castel, J. Thomas, and J.M. Hemsley, A program to acquire deep ocean tsunami measurements in the north Pacific, in Proc. Coastal Zone '87, 33733381, 1987.

LeBlond, P.H., and L.A. Mysak, Wave in the Ocean, Elsevier Scientific Publishing Company, 1978.

Lisowski, M.C., J.C. Savage, W.H. Prescot, and W.K. Gross, Absence of strain accumulation in the Shumagin seismic gap, J. Geophys. Res., 93, 7909-7922, 1988.

Lu, Z., M. Wyss, G. Tytgat, S. Stihler, and S. McNutt, Aftershocks of the May 1993 Shumagin Alaska Earthquake, Geophys. Res. Lett., this issue, 1994.

Nishenko, S.P., Circum-Pacific seismic potential: 1989-1999, PAGEOPH, 135, 169-259, 1991.

Nishenko, S.P., and K.H. Jacob, Seismic potential of the Queen Charlotte-Alaska-Aleutian seismic zone, J. Geophys. Res., 95, 25112532, 1990.

Okada, Y., Surface deformation due to shear and tensile faults in a halfspace, Bull. Seism. Soc. Am., 75, 1135-1154, 1985.

Person, W.J., Seismological notes-September-October 1985, Bull. Seismol. Soc. Am., 76, 1161-1165, 1986.

Ruff, L.J., and B.W. Tichelaar, Moment tensor rate functions for the 1989 Loma Prieta earthquake, Geophys. Res. Lett., 17, 1187-1190, 1990.

Satake, K., The mechanism of the 1983 Japan Sea earthquake as inferred from long-period surface waves and tsunamis, Phys. Earth Planet. Inter., 37, 249-260, 1985.

Satake, K., Y. Yoshida, and K. Abe, Tsunami from the Mariana earthquake of April 5, 1990: its abnormal propagation and implications to tsunami potential from outer-rise earthquakes, Geophys. Res. Lett., 19, 301-304, 1992.

Satake, K., Mechanism of the 1992 Nicaragua "Tsunami" Earthquake, EOS, Trans. Amer. Geophys. Union, 74, p.350, 1993.

Taber, J.J., and J. Beavan, 14 February 1983 earthquake sequence in the Shumagin Islands, Alaska, Bull. Seismol. Soc. Am, 76, 1588-1596, 1986.

Tichelaar, B.W., and L.J. Ruff, Depth of seismic coupling along subduction zones, J. Geophys. Res., 98, 2017-2037, 1993.

F. González, Pacific Marine Environmental Laboratory National Oceanic and Atmospheric Administration, Seattle, WA 98115

L.J. Ruff, K. Satake and Y. Tanioka, Dept. of Geological Sciences, Univ. of Michigan, Ann Arbor, MI 48109-1063.

(Received: September 21, 1993; accepted: November 17, 1993) 